\title{
Cartografías de la mirada, del mapa virtual al recorrido afectivo: la ciudad y sus afueras en La experiencia dramática, de Sergio Chejfec.
}

\section{Cartographies of the Vision, from the Virtual Map to the Affective Journey: the City and its Outskirts in La experiencia dramática, by Sergio Chejfec.}

\section{Resumen}

En La experiencia dramática (2012), la más reciente novela de Sergio Chejfec, se ponen en juego imaginarios geográficos en los que se cruzan los afectos, las tecnologías y diversos regímenes de la mirada. El trabajo plantea un examen de la imagen de la ciudad en esta novela a la luz de esos elementos con el fin de establecer, por una parte, la sensibilidad geográfica como constante de la obra narrativa de Chejfec y, por otra, de articular sus principales implicaciones en el desarrollo del relato, con énfasis en la calidad de dispositivo narrativo que posee la geografía como núcleo de significaciones y posibilidades estéticas.

Palabras claves

Sergio Chejfec, Literatura Argentina, Crítica Literaria, Siglo XXI, Ciudad.

\begin{abstract}
In Sergio Chejfec's La experiencia dramática (2012), there are some geographic imaginaries in which afections, technologies and several regimes of the gaze find a common ground. This article poses an examination of the image of the city in this novel, with the porpouse of stablishing the geographic sensibility as a constant in Chejfec's narrative work, on one side, and of articulating the most important implications in the development of the story, on the other, emphasizing on the narrative device quality geography has as a core of meaning and esthetic possibilities.
\end{abstract}

Keywords Sergio Chejfec, Argentinian Literature, Literary Criticism, 21st Century, City. 
No es sólo difícil saber qué es una ciudad, sino que también es inquietante pensar en lo que hace o en lo que deshace.

Jean-Luc Nancy, La ciudad a lo lejos

En la última novela de Sergio Chejfec, La experiencia dramática (2012), se ponen en evidencia ciertos modos de figurar las complejidades de la proximidad con el otro regidas por el espacio compartido, la geografía urbana, sus afueras y sus modulaciones. Ese régimen territorial - explotado de modo sostenido por Chejfec en toda su obra- se expresa en La experiencia dramática por tres vías: la figuración de la ciudad en relación con los sujetos que la recorren, la noción de representación en su vínculo con lo dramático según lo entiende la novela (y la intensa articulación que tiene dicha noción con la figuración de los espacios), y la problemática identificación de un espacio común en la interacción dialógica entre los personajes, dada por el carácter ambiguo de los límites entre los personajes y entre ellos y el espacio que recorren. Asimismo, procuraré dar cuenta del modo en que estos elementos, que interactúan para dar a la novela su espesor conceptual, encuentran su límite en algunas líneas de fuga que neutralizan el programa de la novela y la llevan a un cierto estado de exceso con respecto a sus propios postulados, haciendo que los olvide momentáneamente.

Como suele ocurrir con los relatos chejfequianos, la anécdota podría resumirse en pocas líneas: dos amigos, Félix y Rose, pasean por una ciudad anónima mientras conversan, se detienen a veces a tomar algo y deambulan hasta los bordes de la ciudad; en esa sencilla línea de acciones, sin embargo, la narración despliega una serie de desvíos y desfases que trastornan la linealidad de la anécdota y evidencian finalmente las preocupaciones formales y conceptuales que se han ido evidenciando progresivamente en la obra más reciente del autor.

En principio, la imagen de la ciudad, formación heterogénea, descripta siempre, en la obra de Chejfec, a partir de su relación de dependencia con su afuera (villa, Conurbano, barrio periférico, campo), como si el elemento extraño 
CATEDRAL Tomada: Revista de crítica literaria latinoamericana / Journal of Latin American Literary Criticism

Cartografías de la mirada, del mapa virtual al recorrido afectivo: la ciudad y sus afueras en La experiencia dramática, de Sergio Chejfec.

en oposición al cual el sueño civilizatorio urbano se construye fuera, sin embargo, imprescindible para la existencia de cualquier imaginario alrededor de la ciudad, no como contraparte debidamente diferenciada, sino más bien como elemento anacrónico que inquieta sus presupuestos (lo extraño que se introduce en lo familiar para perturbarlo); esa imagen, pues, en La experiencia dramática, y siguiendo en cierto sentido el trayecto trazado por la novela inmediatamente anterior del autor, se desplaza hacia la abstracción del mapa digital. Si en Mis dos mundos (2008) el recorrido por la ciudad se visualiza primero en el mapa, procurando una imagen meramente abstracta de la ciudad, aunque aún táctil y física, que luego se matizará en la caminata, en La experiencia dramática la consignación de lo espacial se resume en el punto sobre el plano iridiscente de la pantalla. En cierto sentido, el espacio urbano visualizado previamente no tendrá, como en Mis dos mundos, un correlato más concreto que complemente el visionado del mapa: en esta novela la mirada (que, como en la descripción del Google Maps del inicio, puede ser cenital, lateral, puntual o general) que reduce los lugares a puntos en un plano vasto, conforma un campo abstracto que, en mayor o menor medida, permanece así hasta el final ${ }^{1}$.

Si en Los planetas (1999) ya se había puesto de manifiesto una especie de fascinación del narrador por la imagen de un mapa virtual e inconstatable dibujado por sus recorridos junto a su amigo, en La experiencia dramática esa virtualidad parece encontrar su concreción, paradójicamente, en la imagen digital: "[...] advierte que sus desplazamientos en general se han transformado en algo verificable por partida doble, como si en algún momento hubiese empezado a sembrar un rastro o halo electrónico y ahora tuviera a la mano una forma de asistir a lo que antes hacía pero no podía ver con sus propios ojos" (Chejfec, La experiencia 10). De este modo, el recorrido por el espacio urbano se pliega, para ser verificable, a la doble abstracción del mapa digital donde lo que se pone en juego es la capacidad para mirar y ser mirado, es decir, se convierte en el marco

${ }^{1}$ En la última línea de la novela se lee: “[...] y espera el próximo comentario de Rose que lo rescate del punto imaginario donde está - donde sea que esté-" (Chejfec, La experiencia 164). 
para una puesta en escena: Rose es actriz y, según le cuenta a Félix, uno de los ejercicios de su clase de actuación consiste en contar frente a los compañeros cuál ha sido la mayor "experiencia dramática" de su vida. Esta consigna marca no sólo las reflexiones del protagonista y el ambiguo avance de la narración, sino también la configuración del espacio en la novela; escenario móvil, la ciudad que se recorre es sobre todo el lugar donde la mirada sobre uno mismo y sobre los otros se convierte en mirada espectadora ${ }^{2}$, y donde, asimismo, se despliega una serie de posibilidades para la observación que, al modo de los mapas online, posee una perspectiva múltiple, independiente -o en proceso de emancipación- con respecto a las dimensiones humanas, cenital, por momentos cuasi-divina ${ }^{3}$.

¿En qué deriva el hecho de que la novela coloque, en el lugar privilegiado del íncipit, la imagen del mapa digital? ¿Qué implicaciones tiene el tópico de la tecnología en la figuración de una política narrativa del espacio? En un texto publicado en su blog en 2012, mismo año de la publicación de La experiencia dramática, "Lo que viene después", Chejfec retoma una pregunta especialmente recurrente en su obra ensayística, la que se cuestiona sobre la literatura del futuro. Ya en 2005, en "La dispersión. Sobre la literatura del futuro como contigüidad", el autor se había preguntado sobre los atributos de una literatura del porvenir. Es curioso que en esa ocasión las operaciones discursivas del texto se concentraran más en las posibilidades de torsionar la pregunta que en ensayar, de hecho, una respuesta: Chejfec contestaba al interrogante sobre el futuro con una consideración (espacial) sobre la contigüidad: "La proximidad, en el sentido

\footnotetext{
${ }^{2}$ En este contexto se vuelve necesario distinguir de una noción general de mirada a lo que estoy designando como "mirada espectadora", en la medida en que ésta se vincula con la figura del espectador teatral. Más adelante dedicaré una reflexión más detallada al modo en que entiendo lo teatral en esta novela; por ahora, baste con consignar la distinción mencionada: cuando hablo de mirada espectadora procuro aludir al tipo de mirada que tradicionalmente tiene lugar en el espectáculo teatral, es decir, aquella que observa un entramado de acciones ejecutadas por uno o varios cuerpos en un escenario, generalmente atravesado por la consigna del desarrollo de una historia.

3 "No hace mucho, un párroco quiso graficar en la misa dominical la idea que tenía de Dios [...]. Hizo silencio y agregó que Dios es como los mapas en línea (dijo textualmente "Google Maps"). Puede observar desde arriba y desde los costados, es capaz de abarcar con la mirada un continente o enfocarse en una casa, hasta hacer zoom sobre el patio de una casa" (Chejfec, La experiencia 9).
} 
CATEDRAL Tomada: Revista de crítica literaria latinoamericana / Journal of Latin American Literary Criticism

Cartografías de la mirada, del mapa virtual al recorrido afectivo: la ciudad y sus afueras en La experiencia dramática, de Sergio Chejfec.

cronológico de inmediatez, carece de entidad verdadera para la narrativa; más bien el narrador opera sobre lo próximo en tanto categoría espacial, como cercanía e incluso como contigüidad" (Chejfec, "Dispersión” 28). De este modo, ponía en crisis la idea de narración como sucesión temporal de acontecimientos más o menos dispuestos según - o desviados del- orden cronológico, pero siempre sujetos a él, para postular un conjunto de operaciones y principios constructivos que harían de ella, más bien, el espacio por excelencia del movimiento contiguo, próximo, tendiente a la indeterminación y al desfasaje como efecto de una vecindad radical, con el resultado de un potente extrañamiento de la noción misma de temporalidad ${ }^{4}$.

Por otra parte, en 2010, en el breve ensayo "Introducción" (nótese el carácter inaugural del título), el autor examina la calidad, funciones y alcances de la noción de documento en su obra por venir. El documento en este texto, como señalé anteriormente, lejos de funcionar como elemento constitutivo de un verosímil realista (el efecto de realidad barthesiano), procura introducir la contundencia de lo material en tanto emblema de lo real; los documentos serían una especie de subrayado de las cosas, una "presencia adicional" que "no es una duplicación ni un reflejo, ya que esto es propio de esos mecanismos de ilusión ficcional sensiblemente agotados", sino que tienen la calidad del énfasis, de la repetición, de la acentuación; son descriptos como "ecos o reverberaciones, disfraces transitorios, formas abstrusas de los directo" (Chejfec, "Introducción" $\mathrm{s} / \mathrm{p})$. El desarrollo de estas reflexiones está ligado en "Introducción" a la presencia del yo en la literatura. Para Chejfec el cruce de la mirada documental con la presencia del yo en la escritura literaria es beneficiosa en la medida en que coloca

\footnotetext{
${ }^{4}$ Este es, por otra parte, uno de los programas narrativos del autor desde los comienzos de su trayectoria. Ya en 1998, en una entrevista, se refería en estos términos a las tensiones entre las categorías de espacio y tiempo mientras hablaba de El aire: "La verdad es que el tiempo me interesa menos en sus posibilidades de representación literaria convencional -la serie de procedimientos para ir del pasado al futuro o viceversa, para verificar el desarrollo de una historia, etc.- que en cuanto a sus posibilidades de plegarse a la experiencia de lectura en tanto narración. Quiero decir, para mí difícilmente haya una historia temporal que valga la pena representar, sino más bien un momento, o varios, relacionados a través de variables espaciales" (Berg, Fernández 327).
} 
la mirada del narrador en un "permanente punto subjetivo no redundante, en el sentido de que la misma subjetividad es una condición para desplegar esas miradas y registros que se revelan mejor como puntos de observación, como 'testigos' de la representación documental que ejecutan" (“Introducción” s/p). De este modo, dice Chejfec, pueden salvarse las escrituras del yo de la superfluidad que las amenazaría 5 .

La aparición de los documentos como presencias suplementarias y flagrantes de lo material en su relación con las funciones de la primera persona en el relato parecen marcar la composición de, por ejemplo, Mis dos mundos, aunque, como he procurado sostener, esta concepción de las cosas y del peso de su materialidad presionando la narración e inquietando el verosímil puede rastrearse desde mucho antes. Lo que ocurre con "Lo que viene después" parecería, al menos en principio, redireccionar esa preocupación hacia una zona distinta, y que guarda estrecha relación con La experiencia dramática. En este texto la pregunta por el futuro de la literatura (la propia y la literatura en general, precisa el autor), se plantea y se responde según una lógica temporal cronológica. Lo que viene después es, estrictamente, lo que viene después de ahora, lo que se puede esperar de la literatura en el futuro cercano a la luz de lo que podemos ver hoy. Y, también en contraste con las operaciones del ensayo que se hacía la misma pregunta siete años antes, la enunciación de la pregunta es simple, directa: exige una respuesta y no un cuestionamiento sobre sí misma.

En cualquier caso, en "Lo que viene después" la respuesta se centra en dos elementos principales: la reflexión sobre la perdurabilidad de la escritura y publicación electrónicas en comparación con el formato tradicional del libro físico, y la simulación en tanto nueva posibilidad que brinda la tecnología digital para la literatura y que se serviría de un sistema de referencias estrictamente analógicas para intervenir sobre el universo representado y figurar un "nuevo tipo

5 “ “...] porque el registro de lo documental parece ser la única opción literaria posible para que las experiencias asociadas a la "primera persona" mantengan una presencia no amenazada por la irrelevancia" (Chejfec, "Introducción” s/p). 
CATEDRAL Tomada: Revista de crítica literaria latinoamericana / Journal of Latin American Literary Criticism

Cartografías de la mirada, del mapa virtual al recorrido afectivo: la ciudad y sus afueras en La experiencia dramática, de Sergio Chejfec.

de realismo que encuentra en la simulación al soporte testimonial para proponer nuevos pliegues de sensibilidad donde la subjetividad de hoy cree nuevas escenas" ("Lo que viene" s/p). Los formatos digitales gozarían, según el autor, de cualidades asociadas con la latencia, la "somnolencia", la disponibilidad ininterrumpida, virtual, mientras que el papel y su vulnerabilidad ante el paso de tiempo hacen evidente su caducidad y los peligros que corre. De este modo, la idea más común que considera toda información digital como algo que se olvida y se pierde con la velocidad con que nuevas informaciones emergen, se invierte aquí para contraponer una permanencia de lo digital frente a la inevitable descomposición de la materia. Chejfec llama "escritura inmaterial" a este formato digital, lo que lleva a preguntarse nuevamente sobre la vigencia de los documentos. En "Introducción" se enfatizaba, como vimos, la importancia de una “actitud empática del narrador, o de la narración en general, hacia los objetos físicos, situaciones empíricas o documentos flagrantes en general" ("Introducción" s/p); la propuesta ahora parecería ser diametralmente opuesta. Sin embargo, en la paradójica relación entre el destello fluctuante que forma a la palabra digital sobre la pantalla y su calidad necesariamente material en tanto es, también, escritura ${ }^{6}$, Chejfec encuentra (apoyándose en la noción de "imagen pensativa" de Jacques Rancière), la cifra de su conveniencia: "Esa condición flotante de la escritura sobre la pantalla me hace pensar en ella como poseedora de una entidad más distintiva y apropiada que la física. Como si la presencia electrónica, al ser inmaterial, se acercara mejor a la insustancialidad de las palabras y a la habitual ambigüedad que muchas veces evocan" ("Lo que viene" $\mathrm{s} / \mathrm{p})$.

Es por esto posible suponer que la importancia del documento no ha sido desechada sino, en cualquier caso, reimaginada. En la "escritura inmaterial" que

\footnotetext{
6 "La pensatividad del texto digital provendría del conflicto entre la marca físico-tipográfica inscripta en toda escritura, incluida la digital (ya que se entiende por escritura un sistema de signos que como tales provienen de aquellos que servían como inscripciones), y una condición inmaterial y de postulación provisoria, en el sentido de inestable, que procede del destello virtual" (Chejfec, "Lo que viene" s/p).
} 
parecería ser protagonista del horizonte de "lo que viene después", el documento no desaparece sino que cambia de estatuto: su materialidad no se extingue sino que vuelve a pensarse en los términos de esto nиеvo que se propone para (o se observa en) la literatura actual y la propia obra. Es en este punto donde se conectan los dos ejes centrales de las reflexiones de Chejfec en este texto: la inmaterialidad de lo digital traería consigo los atributos de la simulación para redistribuir los paisajes del relato de un modo analógico ${ }^{7}$ :

La simulación se trata de un sistema de imitación en el que elementos y funciones son tomados de la realidad de un modo necesariamente analógico. Uno puede decir que es una representación, sólo si restringe el significado de esta palabra. Al contrario, la simulación propone un vínculo directo y nunca desviado con el mundo que viene a simular, o imitar. ("Lo que viene" s/p)

Este "vínculo directo" recuerda sin duda al documento tal como se lo había descripto en "Introducción" o incluso en el relato/ensayo "Novelista documental" (2009) ${ }^{8}$. La noción de simulación a la luz de la imagen digital y sus posibilidades para la literatura se encuentra desarrollada en "Lo que viene después" en el marco de la reseña de un relato del escritor español Agustín Fernández Mallo en el que se recrean y comentan los viajes de Robert Smithson desde el Google Maps y con fotos tomadas a la pantalla de la computadora. Más

\footnotetext{
7 Es notable la operación que Chejfec lleva a cabo en este texto: entre la postulación de la perdurabilidad de la escritura digital en contraposición con la caducidad de la física y la comunión de dos términos tradicionalmente antagónicos (digital y analógico), y teniendo en cuenta que en el comienzo del ensayo se justifican las reflexiones por venir en el marco de la posibilidad de una "gran crisis" que estaría viviendo la literatura actual, pero que el autor inmediatamente pone en duda en tanto tal, queda en evidencia la perdurabilidad de la ambigüedad como valor en la poética del autor.

${ }^{8}$ De todos modos, el paso de esas versiones más materiales del documento a la noción de "vínculo" asociada al link, ya puede encontrarse literalmente en algunas breves enunciaciones de Mis dos mundos sobre la vinculación instantánea de elementos heterogéneos en el campo abstracto del internet. Es quizá en esta novela donde el sintagma "vínculo directo" empieza a tener el sentido (o la manifestación) que vemos plenamente desarrollada en La experiencia dramática.
} 
CATEDRAL Tomada: Revista de crítica literaria latinoamericana / Journal of Latin American Literary Criticism

Cartografías de la mirada, del mapa virtual al recorrido afectivo: la ciudad y sus afueras en La experiencia dramática, de Sergio Chejfec.

allá de esta anécdota, lo relevante parece ser la relación que Chejfec postula entre imagen digital y simulación analógica en tanto vínculo con el documento para pensar la literatura actual ${ }^{9}$.

Es en este sentido que procuro pensar, para volver a La experiencia dramática, la configuración del espacio urbano en la novela. Si bien la ciudad aparece en primer lugar como un plano iridiscente abstracto en el que los lugares específicos se consignan con simples flechas o puntos desde una perspectiva cenital, antes que como una abolición de la ciudad en beneficio de la figuración de alguna urbe futurista, cibernética o marcada por flujos de información digital que dan por terminadas las posibilidades del recorrido, propongo pensar este modo de presentar lo urbano y sus límites a la luz del carácter analógico o simulatorio que vengo analizando; lo digital en este caso vendría a sancionar una perdurabilidad (latente, "somnolienta", incluso anticipatoria) de los recorridos. Documental al fin y al cabo, la verificación que permite el mapa digital es enfática, cumple la función de subrayar, de volver a hacer presente, se introduce en la línea argumental como una insistencia en la medida en que enuncia la ciudad sin reemplazarla, duplicándola, haciéndola documento.

De hecho, en una especie de inversión del mito platónico de la caverna, para el narrador los lugares y las cosas del mundo pasan a ser "ejemplo de aquello que de todos modos los mapas dan por sentado", "como si los objetos físicos fueran más una réplica espacial medio adormecida de aquello señalado por los mapas, y encontraran su justificación en esa existencia complementaria" (Chejfec, La experiencia 12). La ciudad que Rose y Félix recorren preexiste en su modo digital, y ese formato le otorga, además, un atributo que es fundamental en la novela: la convierte en escenario. El juego que lleva a cabo el relato está

\footnotetext{
${ }^{9}$ Esta relación no está en absoluto ausente de la novela; son varias las ocasiones en el narrador tematiza al respecto. Aquí un ejemplo elocuente: "No lo cargaba [la Guía-T] porque temiera extraviarse, sino por el placer del simulacro: asistir a su propia presencia y recorrido. Sentía que de este modo el itinerario adquiría consistencia y se perfilaba mejor, se hacía más cierto y real. Más aún, sentía que esta experiencia era en realidad lo único verdadero que la ciudad, y por extensión el mundo, podían ofrecerle [...]" (Chejfec, La experiencia 91 ).
} 
directamente vinculado, como mencioné anteriormente, con la mirada espectadora, como si la configuración del espacio urbano estuviera poniendo siempre en evidencia una cierta cualidad tridimensional y enmarcada, la ciudad como escenografía. Pero, en esa alusión a lo teatral, la forma del mapa digital interviene constantemente: no se trata de un escenario concebido de modo tradicional sino, en todo caso, de un escenario que es también una versión del Google Maps, o que puede ser leído desde el formato particular de ese dispositivo, por eso la perspectiva está constantemente intervenida, forzada a puntos de vista inusuales, como el cenital: en esta novela, el espacio es sobre todo el campo de posibilidades de la mirada, y es la mirada lo que pone en movimiento al relato.

Ejemplificadora de esto es la escena del asesinato al borde del río. En este pasaje de la novela se observa el modo como se pone en movimiento la noción de lo dramático en relación con la mirada y con el espacio, y a éstos en su relación con la imagen digital del principio. Félix y Rose están parados frente al edificio donde está el departamento en el que ella se casó, hace muchos años. Después de mirar por un tiempo indeterminado al segundo piso, esperando ver en la ventana a su amiga, la dueña del departamento, Rose eleva la mirada hasta el piso 25, donde hay un paño de vidrio. Detrás de ese paño imagina a un hombre o, más precisamente, a un personaje: ahí empieza lo que podría ser un ejercicio típico de clases de actuación, consistente en la creación imaginaria de un personaje y una serie de rasgos de su carácter con el fin de representarlo. La deriva imaginaria de Rose lleva a este personaje, mientras espera unas "instrucciones" para llevar a cabo una acción que justificaría su existencia (y que nunca es explicitada), a recordar sus recorridos por la ciudad y sus bordes, generalmente hasta la orilla del río; la ciudad aparece en esta descripción como trasfondo sonoro opuesto a la quietud y el silencio de los confines que se observan: entre el río y los edificios, el personaje narra un espacio que parecería no sólo desierto sino también inexplorado: 
CATEDRAL TOMADA: Revista de crítica literaria latinoamericana / Journal of Latin American Literary Criticism

Cartografías de la mirada, del mapa virtual al recorrido afectivo: la ciudad y sus afueras en La experiencia dramática, de Sergio Chejfec.

Imaginaba que esta experiencia de confrontación módica con la soledad -porque la ciudad mientras tanto se revolvía en sus ruidos y tráficos de todo tipo a algunos centenares de metros- lo transformaba en un ser más ensimismado y propio que de costumbre, porque de un momento para otro se había erigido, podía creer, en el único testigo de esa parte del mundo. (Chejfec, La experiencia 64)

Y entonces, en la quietud de ese recuerdo imaginario, el personaje recuerda un hecho del que fue testigo: un asesinato. Ve cómo alguien descarga una enorme rama de árbol sobre otro, varias veces hasta matarlo. Luego sigue con la mirada el recorrido de una de las hojas de la rama que se ha desprendido y flota empujada por la brisa del río, preguntándose si, en realidad, él había llegado hasta ahí para presenciar el ataque o el trayecto de la hoja. Entonces, cuando es probable que el lector haya olvidado que toda esta producción de imágenes corresponde a un personaje imaginado por Rose, ya que hace más o menos cuatro páginas que no se la nombra y el narrador se ocupa de este $s u b$-personaje como si fuera uno de los principales, la fantasía se corta abruptamente: "Mientras tanto, Rose piensa que es extraño que esta historia no le hubiese ocurrido a Félix; así como estaba, parecía concebida para que él la viviera" (Chejfec, La experiencia 67). Se repone así el carácter artificioso de lo que se acaba de leer, consignándolo como una "historia". Tras esta interrupción, sin embargo, inmediatamente Rose y Félix vuelven a mirar al piso 25 y la historia se retoma:

Y sigue diciendo que desde allí, pese a la gran altura, quizá llegue a fijarse en ellos dos, Rose y Félix, y comience a observarlos sin distraerse mientras intente saber qué tipo de personajes son ellos, qué relación los une y sobre todo qué los lleva a mirar hacia la torre con curiosidad, específicamente en dirección a la ventana donde esta persona espera [...]. Puede asistir al espectáculo de la ciudad desde la altura: las escenas 
que se ven sobre la superficie llegan sin un solo ruido, como si se tratara de un amplio panorama mudo [...]. (Chejfec, La experiencia 67,68 )

El trabajo sobre el cambio de perspectivas pone en evidencia que lo que marca la constitución del espacio es la mirada espectadora; es el observar y el ser observado lo que determina desde dónde se mira la ciudad y a quién corresponde jugar el rol de personaje y a quién el de espectador de las diferentes historias, conocidas o por conocer, reveladas o por imaginarse. Digamos que la cuestión del punto de vista está no sólo en el centro de las operaciones del narrador, sino que está tematizada y trabajada en su relación con la construcción del espacio urbano en la novela. La ciudad se constituye así como escenografía, no sólo de los encuentros entre Rose y Félix en tanto personajes que representan (en el sentido dramático del término) un compendio de funciones y atributos particulares y su interacción singular, sino que en la dinámica general de la novela, cuyo narrador omnisciente la construye como una maquinaria generadora de relatos secundarios que se derivan de los dos personajes principales, la urbe deviene espacio en constante reorganización por parte de la mirada espectadora. Por eso, mientras Félix piensa en la calidad singular y elocuente de los mapas, imagina un nuevo desplazamiento de la perspectiva que haría de él mismo un punto observado desde el cénit de un mapa digital interactivo:

Porque Félix siente una emoción muy difícil de describir cuando se le ocurre pensar, por ejemplo, en el recorrido que está haciendo con Rose mientras conversan, y que ese recorrido pueda inscribirse en un mapa digital activo. Así como él, Félix, es capaz de ajustar sobre la pantalla los ángulos de observación y los tamaños de la superficie, y desplazarse a cualquier área o punto de la geografía sin desviar la mirada, quizás otra persona en ese mismo momento y frente al mismo sector de la ciudad, lo observa a él, Félix, o a los dos, con mayor o menor curiosidad mientras anota algo en un papel cualquiera [...]. (Chejfec, La experiencia 90) 
CATEDRAL Tomada: Revista de crítica literaria latinoamericana / Journal of Latin American Literary Criticism

Cartografías de la mirada, del mapa virtual al recorrido afectivo: la ciudad y sus afueras en La experiencia dramática, de Sergio Chejfec.

En este pasaje y otros que se le asemejan, se conjugan dos tópicos de la novela: por un lado lo que el narrador llama la "conciencia cartográfica" de Félix (La experiencia 90), consistente en una serie de reflexiones recurrentes sobre las distintas variedades y formatos de los mapas (digitales, interactivos, de papel, encuadernados como la Guía-T con sus saltos de páginas en todo punto ajenos a cualquier tipo de analogía con lo que representan, etc.), con énfasis, como he marcado ya, en los mapas interactivos online y, por otro, la recurrencia de una concepción de la ciudad como espacio adecuado, sobre todo, a la mirada espectadora, como escenografía teatral ${ }^{10}$.

La ciudad no goza, entonces, de una entidad estable ni es un paisaje neutro. La ciudad no es, se forma, se redistribuye, se desterritorializa y vuelve a consignar sus propios límites (así sea de modo provisorio) de acuerdo con las intervenciones afectivas, rememorativas y reflexivas de los personajes; para el caso particular de La experiencia dramática, la ciudad vuelve a figurarse de acuerdo con la cartografía abstracta que los personajes generan y que en este caso tiene que ver con el reordenamiento del paisaje de lo urbano en función del impulso del relato hacia la figuración de una (inusual, heterodoxa, móvil) escenografía teatral que depende, a su vez, de una singular dialéctica de la mirada.

Asimismo, este paisaje articula la relación ya usual en la obra de Chejfec entre la ciudad y sus alrededores, sus confines, su afuera. Cuando la imagen de lo urbano responde a este programa conceptual, se muestra a la ciudad en tanto organización cuadriculada, jerárquica y de límites claros; en la mirada cenital que está presupuesta en todo el inicio de la novela (aun cuando la perspectiva es la de los personajes que recorren calles y barrios), la urbe aparece en su formato más

\footnotetext{
10 "Entonces podía hacer de cuenta que durante unos momentos difíciles de precisar transitaría por un lugar sin referencias, medio inexistente, hasta que volviera a verificar en la nueva hoja, en general sobre un ángulo izquierdo o en la parte superior, su calle, la calle por donde en ese momento caminaba, que parecía haber estado a punto de disolverse en un espacio parecido a la nada, y de cuya indeterminación era rescatada gracias a su presencia" (Chejfec, La experiencia 90, 91).
} 
común, como un entramado de manzanas cortadas por calles secundarias y avenidas principales, dividida en barrios más o menos populosos, distribuida según acuerdos sociales o manejos económicos. Como se ve más adelante, la narración articula en distintos puntos algunos modos de deshacer este entramado con parajes urbanos que lo ponen en crisis y lo reimaginan. Lo que queda por fuera de los límites de la ciudad (límites que no están determinados tanto de modo geopolítico como lo están de modo visual -el contraste de paisajes- y narrativo lo que el cambio de registro entre el entramado cuadriculado de calles, avenidas y edificios versus el río, su luz tenue y el silencio y quietud de sus orillas, o la zona abandonada de los galpones, habilita para el relato-) funciona no sólo como espacio de contraste sino que reimagina lo urbano deshaciéndolo: tanto la zona ribereña del pasaje anterior, que oponía al bloque sonoro urbano una quietud que preparaba la escena del ataque (y su otra cara: el vuelo tranquilo de la hoja) como la zona de los galpones industriales abandonados, que habilita, en cambio, el encuentro sexual entre Félix y Rose, tienen su forma de exhibir, diría, el casco urbano reducido a sus elementos primarios, como si esos confines, en su soledad silenciosa, tuvieran la elocuencia del recuerdo que vuelve o la potencia de lo que, habiendo sido desterrado, retorna de algún modo. Por eso en las dársenas el personaje inventado por Rose escuchaba la ciudad a sus espaldas y por eso, en los galpones abandonados, Félix se encuentra con un escenario del que la ciudad a sus espaldas sería una versión paralela:

Cuando andan juntos por ahí Félix siente que la ciudad, con toda su maquinaria de funcionamiento más o menos sincronizada, existe como versión paralela del silencio y abandono preponderantes en estas manzanas. Es algo parecido a una ficción física: un escenario fabricado se ha erigido para que Rose y Félix, los dos juntos y cada uno, con la parte de nociones de verdad que les corresponden, se sientan a sus anchas [...]. (La experiencia 132) 
CATEDRAL Tomada: Revista de crítica literaria latinoamericana / Journal of Latin American Literary Criticism

Cartografías de la mirada, del mapa virtual al recorrido afectivo: la ciudad y sus afueras en La experiencia dramática, de Sergio Chejfec.

En este juego de equivalencias y desequilibrios entre la identidad y la apariencia, entre el original y su versión, que nunca coagula del todo, lo que se postula no es, precisamente, una entidad urbana de la que estos desvíos serían versiones o escenarios; por el contrario, la ciudad se juega en el límite entre lo visible y lo invisible, entre el abandono y la quietud que se ven y la actividad y el movimiento que se escuchan a lo lejos. Se trata de un sistema de simulación que excluye la identidad y, una vez más, se juega enteramente en un régimen de ambigüedad avocado a la desestabilización de los presupuestos previos al trazo de la cartografía afectiva y rememorativa de los personajes, mientras establece vínculos materiales con los documentos que los recorridos proporcionan. Félix, en este sentido, y siendo el núcleo al que vuelve todo el tiempo el narrador para avanzar en el relato, concentra los atributos de este sistema de representación:

[...] está acostumbrado a las señales difusas y a los equívocos en general, a que las cosas sean lo que aparentan y algo distinto, muchas veces apenas desviado. No su contrario, porque no le gustan las opciones excluyentes y algo en lo profundo de su sensibilidad tiende a desconocer los opuestos. Para Félix no existe lo íntegro ni lo entero, también la idea de totalidad le parece imposible, y por ende según él las cosas difícilmente alcanzan a complementarse. (La experiencia 128 )

A partir de estas afirmaciones podría entenderse la calidad del espacio urbano en La experiencia dramática: el traspaso de las fronteras de la ciudad hacia zonas deshabitadas o abandonadas figura un desplazamiento módico, una inclinación discreta antes que un contraste radical. Así como ocurría en El aire (1992), donde la miseria urbana iba mostrándose paulatinamente y gracias a la repetición obstinada de los recorridos por los mismos lugares, donde parecían emerger ante la vista fenómenos que antes no se habían registrado, en esta novela las zonas aledañas a la ciudad o, más precisamente, las áreas de ésta que han sido 
relegadas y que aún exhiben las señales de su actividad pasada, no funcionan como lo otro de lo urbano sino, más bien, como su versión apenas trastornada, algo que recuerda constantemente, quizá, el origen y destino de todo el rumor citadino.

Quizá por eso las descripciones de estos parajes abandonados y lo que producen tanto en Rose como en Félix ocupan un lugar privilegiado (por su extensión y detalle descriptivo así como por su ubicación, hacia el final de la novela) en la historia: se trata de un espacio que condensa esta disposición estética de Félix y del narrador hacia la proximidad extrema antes que hacia el contraste. Cuando los personajes deambulan por la zona de los galpones industriales abandonados, se pone de manifiesto una cierta cualidad del espacio que resignifica y reorganiza la ciudad que quedó atrás y, del mismo modo, la cartografía emocional de los personajes; la magnitud de los galpones y su modo de repetirse de modo serial, el abandono de las calles de la zona y del interior de los edificios, la quietud en que los escombros permanecen como a la espera, vehiculizan una cierta sensibilidad tanto en Félix como en Rose: para él, de intensa emoción geográfica, de empatía profunda con la quietud y el abandono del paisaje, para ella, de temor ante un peligro tan invisible como inminente, algo que tiene que ver con lo oscuro que se mueve solapadamente: "en medio de la oscuridad nocturna podrán verse los reflejos medio inertes de luces esporádicas, muchas de ellas exhibiendo un extraño movimiento de sombras tras las zonas de estribaciones urbanizadas, dibujando con sus titilaciones nuevos pozos de oscuridad" (La experiencia 129). Como reza el epígrafe de este trabajo, el pasaje entero parece postular de este modo meramente descriptivo, la forma como una ciudad se deshace y deshace sus propios regímenes. Es notable la plasticidad con la que la narración se detiene en el paisaje de la zona ex industrial, en toda su grandeza en desuso, así como la conmoción estética de Félix ante lo que ve: este espacio del contraste lumínico, de la convivencia pacífica entre volumen y vacío, entre "duración y caducidad" (La experiencia 132), es lo que habilita, en la novela, una serie de reflexiones exclusivamente referidas a lo visual y lo sonoro; 
CATEDRAL Tomada: Revista de crítica literaria latinoamericana / Journal of Latin American Literary Criticism

Cartografías de la mirada, del mapa virtual al recorrido afectivo: la ciudad y sus afueras en La experiencia dramática, de Sergio Chejfec.

como si el impulso razonante de la voz narrativa se interrumpiera por un momento para limitarse a describir con detalle unos ciertos efectos de la luz solar ingresando por rendijas y cortando la penumbra interior y, con ella, el hermetismo de los galpones con el recuerdo visual del exterior, o la opacidad del silencio que habilita la emergencia de algo más, una presencia suplementaria que no se percibe pero se sospecha.

Lo cierto es que este pasaje de la novela establece un nuevo régimen de la mirada que no coincide con la mirada espectadora tal como la he venido describiendo. En la zona de los galpones abandonados se pone de manifiesto un modo de ver que ya no iría en la dirección única del hipotético escenario que sería la ciudad y que neutraliza el sistema según el cual venía funcionando el relato. Quiero decir que se hace patente un cambio en la mirada: entre el juego de perspectivas que forma y reforma constantemente un espacio constituido como escenario y la detención en la observación de esta zona de abandono, lo que cambia es que en el segundo momento, la mirada es afectada por el objeto o el lugar en que se fija. Los galpones interpelan a Félix, ponen en suspenso el programa constructivo de la novela y desarman momentáneamente el sistema que se triangula entre la mirada espectadora, el mapa digital y el tramado teatral del espacio. Los enormes espacios vacíos que Félix observa un tanto extasiado le devuelven la mirada, emiten rumores, prefiguran una presencia sub-humana: ponen en juego un nuevo tipo de intercambio en la medida en que, gracias a la sensibilidad geográfica del protagonista, figuran una densidad particular que deja de ser muda, que ya no es el producto de una mirada que crea personajes. Estos volúmenes de vacío se muestran capaces de devolver la mirada (de ahí que los personajes se sientan observados aunque lo que caracteriza a estos espacios es el estar vacíos) y de ese modo inquietan los presupuestos según los cuales se constituyen los personajes en el sentido teatral del término ${ }^{11}$.

${ }^{11}$ Sigo aquí los postulados de Georges Didi-Huberman sobre la mirada. Para el crítico francés, ésta se constituye en su relación con la capacidad del objeto observado para devolver la mirada, escindiéndola; es a través del síntoma en tanto señal anacrónica que viene desde el objeto 
Rose también se fija en el silencio, que se hace más espeso por efecto del inmenso vacío del lugar, sin verdaderos obstáculos para los ruidos, y de la atmósfera detenida, dejando a cualquier visitante, ellos en este caso, a merced de un rumor profundo que recuerda el sueño de una bestia, o por lo menos de algo incontrolable [...]. (La experiencia 134)

Ese rumor, que se asocia con el peligro y, más específicamente, con el peligro de estar siendo observados, vuelve a habilitar, tras el breve paréntesis fenoménico, las reflexiones de la voz narrativa: "Son momentos en los que ambos sienten vergüenza o miedo ante la posibilidad de haber sido observados. El lugar es tan profundo que cualquiera, aun sin esconderse, podría vigilarlos desde la oscuridad y no llamar su atención" (La experiencia 134). Este momento marca el final de la digresión plástica del narrador, ese pasaje que pone en suspenso el tono general del relato (un tono razonante, explicativo, que busca transparentar en todo momento sus propias estrategias argumentativas) y vuelve a figurar el espacio como una escenografía en la que, siempre, existe la posibilidad de ser personajes ante un espectador invisible. Y así, retorna también la explicitación de la relación entre los sujetos y el espacio (o entre los personajes y la escenografía) que marca el desarrollo del relato. Se dice que Félix tiene un "punto de vista adaptativo, según el cual los individuos tienden a plegarse al ambiente circundante; a la

observado y que inquieta la relación del ver que la mirada puede volverse ineluctable. En este sentido, plantea la mirada como "obra de pérdida", entendiendo "obra" como trabajo, el trabajo de la propia escisión. Uno de los ejemplos más elocuentes de este estudio sobre la mirada es el de alguien que mira una tumba, y que, ahora, encuentro vinculado con la observación absorta de Félix sobre los galpones vacíos atendiendo a la particular sensibilidad espacial del personaje: “¿Qué sería un volumen, un cuerpo que mostraría la pérdida de un cuerpo? ¿Qué es un volumen portador, mostrador del vacío? ¿Cómo mostrar un vacío? ¿Y cómo hacer de este acto una forma que nos mira? [...] Ejemplificación máxima de la escisión del ver: por un lado está lo que veo de la tumba, la evidencia de un volumen (masa, forma, tallado, etc.) y por el otro está lo que me mira, y lo que me mira es una situación tal que ya no tiene nada de evidente, puesto que, al contrario, se trata de una especie de vaciamiento. Un vaciamiento que ya no concierne en absoluto al mundo del artefacto o el simulacro, un vaciamiento que allí, ante mí, toca lo inevitable por excelencia: a saber, el destino de un cuerpo semejante al mío, vaciado de su vida, de su palabra, de sus movimientos, vaciado de su poder de alzar sus ojos hacia mí. Y que sin embargo en un sentido me mira -el sentido ineluctable de la pérdida aquí en obra" (Didi-Huberman Lo que vemos 18, 19). 
CATEDRAL Tomada: Revista de crítica literaria latinoamericana / Journal of Latin American Literary Criticism

Cartografías de la mirada, del mapa virtual al recorrido afectivo: la ciudad y sus afueras en La experiencia dramática, de Sergio Chejfec.

pasividad cuando es pasivo y a la tensión cuando es tenso o activo [...]" ( $\mathrm{La}$ experiencia 131); este impulso del protagonista encuentra su punto de mayor intensidad en el paisaje que más lo conmueve, el de los galpones abandonados. A la escucha del rumor que nace del silencio de esas construcciones tan monumentales como obsoletas, Félix (y, con él, la voz narrativa ${ }^{12}$ ) expone nuevamente la concepción del espacio (de este espacio periférico pero, también, en consecuencia, de la ciudad céntrica), el modo en que la novela lo entiende o construye, la imagen que forma:

Esa tendencia adaptativa de la destrucción, que una vez consumada se somete a las condiciones del entorno admitiendo distintas denominaciones, como abandono, devastación, ruina o decrepitud, intriga fuertemente a Félix y le resulta inspiradora. No porque la vea como metáfora del capitalismo ni mucho menos como síntoma de un desarrollo urbano particular, aunque en realidad también podría verlo de esa manera, sino porque encuentra en ella un reflejo de sí mismo. O mejor, más que un reflejo, siente que opera una sintonía. (La experiencia:

Esta "sintonía", efecto de una vecindad o contigüidad física, se da como evento adaptativo producto de la cercanía, es decir que tiene que ver con la capacidad de la destrucción (de un acontecimiento que se consuma, que tiene lugar desorganizando lo unitario en una suma inorgánica de sus partes) para reacomodarse al paisaje visible modificándolo levemente, y del sujeto para

\footnotetext{
${ }^{12}$ Insisto en mantener en la ambigüedad la diferenciación entre el narrador y el protagonista (e incluso tomando nota de que ya la diferenciación de estas categorías persiste únicamente por cuestiones metodológicas); se trata, a mi juicio, del único modo de hacerle justicia a la matriz narrativa de la novela. Existe sin duda un "punto de vista adaptativo" también entre el narrador y el personaje (en ocasiones también con Rose). No es que, como ocurre en otras novelas del autor, la voz pase de un personaje a otro, o de la omnisciencia a la primera persona indistintamente, sino que, aquí, existe una proximidad intensa que deriva en ocasiones en la adaptación.
} 
plegarse a esa organización que exhibe aún las señales del desorden pero ya acoplada al horizonte general ${ }^{13}$. Esto recuerda a la imagen que da la tónica general a Los planetas, novela de la posdictadura argentina, donde los eventos destructivos de la Historia (y de los trayectos individuales) terminaban plegados al paisaje general de quietud para figurar el movimiento común de todos los elementos y de todos los sujetos después de sí mismos, hacia un horizonte que se rige por fuerzas ajenas a la voluntad ${ }^{14}$. En los pasajes de la zona abandonada de galpones, algo de esto vuelve a ponerse de manifiesto como avatar sentimental o intelectual de un personaje en trance de representarse a sí mismo (quizá, también, como fondo de sentido del relato, recordatorio de un destino ineludible).

De todos modos, este largo pasaje de la novela representa una de sus líneas de fuga con respecto al armado conceptual basado en la relación entre lógica teatral, mirada espectadora y la imagen del mapa digital, en el sentido en que pone en suspenso esa estructura y la inquieta derivando sus elementos hacia una zona de indeterminación que da cuenta de un destino común a toda representación. Si el mapa digital, en su materialidad analógica, proporcionaba un vínculo directo con el espacio recorrido, una especie de doble verificación, siempre disponible a la mirada espectadora que puede convertir esos recorridos en las acciones de personajes interpretando sus propios dramas, de las intervenciones de los personajes sobre la ciudad, hay un resto que permanece inmune a la simulación. Quiero decir que no todo en el relato responde a la lógica que he venido intentando exponer, la que vincula documento digital con mirada espectadora y con ciudad como escenografía. Así como los confines de la ciudad, con su silencio tan pacífico como desafiante, tienen un modo de desarmar o

${ }^{13}$ El diálogo que Chejfec establece con Sebald es constante, y no se limita únicamente a procedimientos en común. En este caso la evocación a Sobre la historia natural de la destrucción (1999) es evidente, aunque la apuesta en La experiencia dramática está menos ceñida a la historia en el sentido de que si en el libro de Sebald lo que se piensa es la destrucción desencadenada por un avatar mayor de la Historia, en la novela de Chejfec se trata de un deterioro módico, paulatino, producto del movimiento común de los acontecimientos del mundo.

${ }^{14}$ Trabajé los alcances de la geografía y el paisaje como dispositivos narrativos capaces de dar cuenta de los rastros de cierto tipo de violencia política en "La ruta de los astros. Cuerpo territorio y movimiento en Los planetas de Sergio Chejfec", Andrea Ostrov (ed.), 2015. 
CATEDRAL TOMADA: Revista de crítica literaria latinoamericana / Journal of Latin American Literary Criticism

Cartografías de la mirada, del mapa virtual al recorrido afectivo: la ciudad y sus afueras en La experiencia dramática, de Sergio Chejfec.

descomponer todo el armado geométrico de la urbe y, con él, el programa conceptual de la novela, poniendo en evidencia, como una radiografía, sus partes primarias, y suspendiendo por un momento los presupuestos que la rigen, existen también líneas de fuga que perturban esta lógica y desestabilizan los propios presupuestos de la novela; esas líneas de fuga son, también, los recuerdos de los personajes que establecen un instancia para lo irrepresentable, para lo que ocurre por fuera de la lógica de la mirada espectadora porque adviene de modo intempestivo y, como en la zona de los galpones, su manifestación es predominantemente fenoménica: la ficción del pasado no es sino la "ficción de la luz del pasado" (La experiencia 121).

Así, los eventos del pasado que entran en la lógica teatral (la boda de Rose, la figura moribunda del hermano de su marido, que aún pueden ser presentizados por la maquinaria teatral de la novela) se decantan por una de sus partes que permanece inaprehensible a esa lógica: los objetos del pasado o su luz particular irradian el presente de un modo singular, ajeno al impulso simulatorio analógico, escénico- general del relato. A la vez que funcionan como documentos, figuran un exceso de sentido (aun después de haber perdido, en el caso de los objetos, su valor de reliquia) que se fuga hacia un fondo de indeterminación irrepresentable, lo que queda después de que el recuerdo declina hacia su ineludible proceso de "decoloración" (La experiencia 97 ):

Todos estos objetos son pruebas de lo sucedido, pero por algún motivo no testimonian la vida de la que provienen. Algo se ha roto, advierte el marido de Rose, según ella. Una vaga intuición le sugiere que esas cosas, aun en su dispersión retórica más alocada, pertenecen al origen, y por lo tanto no se presentan como puntos sucesivos sino como préstamos acumulativos del pasado, todos de una vez. (La experiencia 112) 
Y en este sentido puede pensarse el pasado, o más precisamente el recuerdo de algunas de sus condiciones, en su relación tanto con lo que se denomina "el origen" como con la geografia ${ }^{15}$. El personaje de Félix es un emigrado, la ciudad que recorre con Rose no es su ciudad. Para él los recuerdos, sus ideas ambiguas sobre el destino y el origen, están planteadas en función de una sensibilidad fundamentalmente geográfica. No por nada la imagen del mapa, que inaugura la novela, regresa continuamente durante todo el relato y se constituye como una de las reflexiones centrales del mismo; Félix asimila entonces las nociones de recuerdo, pasado, origen y destino a un régimen geográfico que moldea todas las reflexiones y el curso de la narración, así como habilita también las líneas de fuga que especifiqué anteriormente. Se trata de una suerte de sistema que organiza los acontecimientos plegándolos a la figuración de la geografía como matriz del desarrollo narrativo; en ese sentido puede pensarse el programa de La experiencia dramática, en tanto exploración de las posibilidades estéticas y narrativas de la ciudad como forma y como entidad inestable y extranjera, a la luz de las preocupaciones específicas que he venido trabajando, como el documento digital, la noción de lo dramático, la dialéctica de la mirada y la calidad geográfica del recuerdo, en tanto desencadenante y generador del relato: "Desarraigado de su comarca y no habiendo encontrado nada que compense la falta, el pasado o el tiempo en general terminan siendo una cadena de circunstancias asociadas a los lugares [...]" (La experiencia 135).

Finalmente, me pregunto qué ocurre con el espacio de lo común en esta novela. Si por una parte existe la ciudad como eje del desarrollo de la narración, y por otra una noción, así sea abstracta y fundamentalmente operativa, de teatralidad; y si, en resumen, la novela entera es el relato de uno o varios paseos de dos personajes que conversan, ¿qué ocurre con lo común?, ¿cuál es el ámbito

\footnotetext{
15 "Y que si algo lo seguía vinculando al mundo no era una línea de tiempo ni un trazo de hechos ordenados de un modo más o menos cronológico o convencional, tampoco psicológico o sentimental, sino que el vínculo estaba dado por una mezcla, un 'mix' dijo, entre lugares verificables de la geografía y momentos específicos del pasado [...]. Y de un modo que resultaba difícil de explicar, la noción de origen venía a resultar de ese mix entre geografía y tiempo sobrevenido" (Chejfec, La experiencia 85).
} 
CATEDRAL Tomada: Revista de crítica literaria latinoamericana / Journal of Latin American Literary Criticism

Cartografías de la mirada, del mapa virtual al recorrido afectivo: la ciudad y sus afueras en La experiencia dramática, de Sergio Chejfec.

de su articulación, o cómo figura el texto la noción de lo comunitario? Los ejes que dan forma a La experiencia dramática convocan por sí mismos la cuestión: ¿a qué desvíos y desfases se la somete, de qué modo aparece? ${ }^{16}$

En principio, entonces, la historia es sobre dos amigos que se encuentran regularmente para caminar y conversar. El diálogo que se entabla, empero, poco tiene que ver con un régimen común de intercambio; por el contrario, existe un desfase rítmico que marca la interacción. Si en Los planetas los recorridos de los amigos estaban marcados por la inacción y por diálogos escasos, lo mismo que con Delia y el protagonista de Boca de lobo, en La experiencia dramática pareciera que todo el tiempo alguien habla (generalmente Rose) pero los tiempos de recepción y las réplicas responden a una temporalidad heterogénea. Incluso en la relación de diálogo que establece con Glosa (1985) de Juan José Saer, esta novela opera un extrañamiento aun más marcado. Quiero decir que si al nivel de la trama, por ejemplo, en Glosa, Leto y el Matemático participaban de un diálogo que abría líneas de evasión en cada uno según sus propios recuerdos o

${ }^{16}$ La ciudad en tanto constructo cultural y núcleo de imaginarios histórico-políticos y estéticos se ha debatido históricamente entre la comunidad y el aislamiento del individuo. En la medida en que la urbe constituyó uno de los ideales del Iluminismo (cf. Lehan, xiii-xvi), figuró las aspiraciones a una comunidad regida por la razón, el bien común y el progreso. Las tensiones entre estos ideales y el conocido solipsismo del hombre en la ciudades en que finalmente derivaron fue una preocupación central desde la emergencia de los primeros estudios sociológicos sobre lo urbano: "A shared belief among these emerging urbanists [G. Simmel, M. Weber, E. Durkheim] was that modern man, placed under great stress, feared becoming superfluous and anonymous" (Lehan 7), y así también en la literatura, desde el realismo al posmodernismo, aunque en el momento actual es improbable que sobrevivan imaginarios comunitarios alrededor de la urbe. Cabe más bien pensar alrededor de las nociones de diversidad y multitud, que por vías heterogéneas pueden redirigir hacia modos post-utópicos de lo común (Lehan 8). En lo que concierne al teatro, como marqué ya, la novela trabaja con una noción abstracta de teatralidad, con lo cual la pregunta sobre la comunidad que convocaría es casi ineludible. En palabras de Rancière: “"El teatro sigue siendo el único lugar de confrontación del público consigo mismo en tanto que colectivo'. En un sentido restringido, la frase sólo pretende distinguir la audiencia colectiva del teatro de los visitantes individuales de una exposición o de la simple adición de las entradas al cine. Pero está claro que significa algo más. Significa que el 'teatro' es una forma comunitaria ejemplar. Conlleva una idea de comunidad como presencia en sí, opuesta a la distancia de la representación" (Rancière 13). Si bien Rancière enuncia estas consideraciones tradicionales con el fin de cuestionarlas desde sus presupuestos, lo que procuro es utilizar nociones fuertemente ligadas por la tradición a los ejes de la novela para mostrar el modo que ella tiene de desarticularlos sin desecharlos del todo. Es decir, una vez convenido el hecho de que tanto ciudad como teatro apelan a un espacio común y a cierta noción de comunidad, examinar los modos en que el relato trata con esa noción. 
preocupaciones gatillados por lo que el otro decía, y si el trabajo era sobre la presentización de las versiones de un hecho nuclear (la fiesta de Washington), lo cual hacía emerger un pulso divergente en el intercambio dialógico, en $L a$ experiencia dramática la entidad misma de los sujetos en diálogo es inestable en virtud de los movimientos de la voz narrativa, que no deja de derivar el relato hacia personajes paralelos, creados por los dos personajes principales, y de ocuparse de ellos en el mismo nivel en que se ocupa de Félix y Rose, sin establecer jerarquías de ningún tipo. Así, el relato de la relación tortuosa del marido de Rose con su hermano, la experiencia del recuerdo tras su muerte, el personaje inventado por ella en el piso 25 del edificio donde se casó, o incluso los tres hermanos mudos, personajes de la obra de teatro que Félix imagina mientras Rose le cuenta algo, gozan del mismo tratamiento por parte del narrador. En esta novela no existen las versiones, el régimen rizomático (y apelo sobre todo a la plasticidad de la imagen del rizoma en este caso) del desarrollo narrativo escamotea las posibilidades de establecer la autonomía de dos sujetos que conversan.

En este sentido, establecer claramente un espacio para lo común se torna delicado; parecería más idóneo pensar en un régimen del encuentro como política narrativa de la comunidad en esta novela, como si los personajes "tuvieran órbitas independientes aunque no del todo ajenas, organizadas según pautas de aproximación más que de contacto" (La experiencia 57). Entre la verborragia de Rose y el carácter más bien inclinado al silencio y a la discreción de Félix, la conversación no es tanto una instancia de equilibrado intercambio marcado por la emisión, la recepción y la réplica como una puesta en escena enigmática y desbalanceada: "Así, cada conversación se desarrollaba como una escena misteriosa donde el diálogo era la forma de un rumor, de un secreto apenas entredicho o de una melodía única para la que tenían entrenado el oído en la misma medida, probablemente, suponía Rose, desde antes de poder hablar" ( $L a$ experiencia 57). Más allá de que la lengua de Rose no es la misma que la de Félix (de ahí que Félix siempre la escuche un poco fascinado, como si la lengua 
CATEDRAL Tomada: Revista de crítica literaria latinoamericana / Journal of Latin American Literary Criticism

Cartografías de la mirada, del mapa virtual al recorrido afectivo: la ciudad y sus afueras en La experiencia dramática, de Sergio Chejfec.

extranjera de Rose le entregara una versión distinta de todas las cosas a las que él puede acceder directamente, especialmente la ciudad), la disposición de cada uno es radicalmente distinta. Mientras Rose no para de hablar, Félix, en la línea de los protagonistas chejfequianos, siempre se encuentra un poco incómodo ante la situación de exponerse:

Félix viene de una familia sin historias, con pocas cosas para contar. Silencios prolongados alrededor de la mesa, las esporádicas conversaciones en un eterno y apabullante presente, etc. Por lo tanto, es muy difícil para él imaginar escenas alrededor de un idioma común. Y al contrario, algún esquema de tipo escénico, con piezas o personajes no necesariamente verbales, pero comprometidos con su papel y con la representación colectiva, donde los hechos se desarrollen con una consistencia que no precise de subrayados ni de esfuerzos [...]. ( $L a$ experiencia 74,75$)$

Como se ve en esta cita, para Félix un esquema escénico esquiva el problema de la carencia de un idioma común, con lo cual también puede pensarse que lo teatral en esta novela aparece después de haber sido torsionado fuertemente desde sus enunciados fundamentales, lo que puede también ser colegido en el hecho de que la obra teatral que imagina Félix, que carece de palabras y que consta de apenas unos pocos y discretos movimientos de los cuerpos en el escenario, tiene como tema la familia, los personajes son tres hermanos, quizá una de las formas más directamente asociadas a la comunidad. Parecería que lo común en este relato es la palabra devenida rumor, la lengua extranjera, la identificación casual y esporádica con la rareza del otro, un régimen del gesto antes que de la comunicación ${ }^{17}$; un modo de diálogo, en fin, más asociado al destello de una

\footnotetext{
${ }^{17}$ Uno de los personajes con los que Félix siente mayor empatía es el marido de Rose, con quien nunca habla. Lo que emerge de común entre los dos se da siempre en el régimen azaroso del encuentro en distintos puntos de la ciudad y se basa enteramente en la actitud del personaje: "[...]
} 
convergencia de la sensibilidad que enseguida se apaga que al intercambio efectivo de enunciados, que sería la base de la comunidad entendida como "manera de ocupar un lugar y un tiempo, como el cuerpo en acto opuesto al simple aparato de las leyes, un conjunto de percepciones, de gestos y de actitudes que precede y preforma las leyes e instituciones políticas” (Rancière 13).

Es ese el modo de aparición de un espacio común en La experiencia dramática: para Félix, que no guarda recuerdos de la ciudad que recorre con Rose, no es tanto lo que ella pueda decir, ni los lugares a los que lo pueda llevar (ya que es la que usualmente guía los paseos de ambos), no es el contenido de sus palabras y por tanto no es la información que pueda proporcionarle ni las anécdotas que pueda confiarle lo que logra hacerlo experimentar afectos relacionados con la vida en común. Por el contrario, parecería ser el tono de Rose lo que en ocasiones le permite al extranjero sentir que algo del pasado de esa ciudad que ahora habita le compete ${ }^{18}$.

No ha sido la transparencia del aire o el diagrama de las calles, la altura de la ciudad o la presencia del río, la época del año ni el estado del tiempo, tampoco el perfil irregular de los edificios, ni influyó ninguna foto rescatada de épocas pasadas, y por supuesto no intervinieron los recuerdos, ya que no existían en el caso de Félix; no, se trató solamente

el carácter más conmovedor del marido es esa constancia en mantener la voluntad menguada, como si se tratara de la única decisión verdadera tomada en mucho tiempo. De los rasgos que ambos podrían tener en común [...] la suspensión de la voluntad, que a veces pone de manifiesto como un intervalo en la cadena de acciones, en la experiencia asumida como propia, inesperado por otra parte porque parece consistir en un descanso, como si alguien se asomara al vacío de la indecisión preguntándose si las cosas en general se tratan sólo de un juego o del más deliberado destino; esa renuncia de la voluntad, de cualquier intención y casi hasta de cualquier deseo humano [...], es lo que Félix encuentra de más parecido a su propio carácter y frente a lo cual esgrime naturalmente una profunda y automática solidaridad [...]" (Chejfec, La experiencia 57, 58).

${ }^{18}$ Me refiero a la noción de tono de Blanchot (que aquí traslado del escritor a uno de los personajes), que responde mejor al régimen de La experiencia dramática, es decir, no el estilo ni la "calidad" del lenguaje, tampoco la voz ni lo que dice, "sino la intimidad del silencio que impone a la palabra, lo que hace que ese silencio sea aún suyo, lo que permanece de sí mismo en la discreción que lo aparta" (Blanchot 23). 
CATEDRAL TOMADA: Revista de crítica literaria latinoamericana / Journal of Latin American Literary Criticism

Cartografías de la mirada, del mapa virtual al recorrido afectivo: la ciudad y sus afueras en La experiencia dramática, de Sergio Chejfec.

de la forma como respondió Rose, que hizo retroceder el tiempo para rescatar la luz del pasado que, aunque naturalmente abolida, acaba de volver bajo otra forma y sumerge a Félix en una especia de ilusión geográfica. (La experiencia 121)

Ya que la sensibilidad de Félix es, como marqué anteriormente, fundamentalmente geográfica, es en los momentos fugaces de entrega a estas ilusiones geográficas donde hay que rastrear la modalidad de lo común en esta novela. Cualquier figuración de comunidad global (para remitir a la constelación conceptual que podría derivarse de la recurrencia a los mapas digitales), ya sea celebratoria o crítica, está abolida en beneficio de una forma de espacio común marcada por estos momentos en que la narración interrumpe el despliegue de sus propios presupuestos para postular un paréntesis fenoménico que genera encuentros, con otros o con el espacio. Atendiendo a la imagen de las órbitas que parecerían regir los trayectos de los personajes, que "circulan por pautas de aproximación más que de contacto" (La experiencia 57), la forma de lo común parecería constituirse según un régimen aproximativo, cinético y fundamentalmente espacial. Se trata de una forma de comunidad en continua desintegración, no basada en enunciados ni en experiencias comunes, sino apenas en la tonalidad de una voz cuando es posible abstraerse de lo que dice y que permite que súbitamente el pasado de un lugar desconocido regrese con una luz familiar, o el modo como un rayo solar entra oblicuo a iluminar una zona de escombros para habilitar la emergencia de un recuerdo de -abstracta, anómalapertenencia. 
CATEDRAL TOMADA: Revista literaria latinoamericana / Journal of Latin American Literary Criticism Daniela Alcívar Bellolio

\section{Bibliografía}

Alcívar Bellolio, Daniela. "La ruta de los astros. Cuerpo territorio y movimiento en Los planetas de Sergio Chejfec". Cuerpos, territorios y biopolítica, Andrea Ostrov, editora, Buenos Aires: NJ, 2015. 15-36.

Berg, Edgardo. "Fuera de lugar. Entrevista a Sergio Chejfec". Revista del CELEHIS. 11 (1999): 319-332.

Blanchot, Maurice. El espacio literario. Madrid: Editora Nacional, 2005.

Didi-Huberman, Georges. Lo que vemos, lo que nos mira. Buenos Aires: Manantial, 1997.

Chejfec, Sergio. El aire. Buenos Aires: Alfaguara, 2008 [1992]. . Los planetas. Buenos Aires: Alfaguara, 1999. . Boca de lobo. Buenos Aires: Alfaguara, 2000. . "La dispersión. Sobre la literatura del futuro como contigüidad". El punto vacilante. Literatura, ideas y mundo privado. Buenos Aires, Norma, 2005. . Mis dos mundos. Buenos Aires: Alfaguara, 2008. . La experiencia dramática. Buenos Aires: Alfaguara, 2012

. "Novelista documental". Parábola anterior. 2009. . http://parabolaanterior.wordpress.com/2009/08/03/novelista-documental/. Mayo 2016.

.'Introducción”. Parábola anterior. 2010.

http://parabolaanterior.wordpress.com/2010/10/14/introduccion/. Mayo 2016.

. Parábola anterior. "Lo que viene después". 2012.

http://parabolaanterior.wordpress.com/2012/98/12/lo-que-viene-despues/. Mayo 2016.

Lehan, Richard. The city in literature. University of California Press., Berkeley, 1998 
CATEDRAL TOMADA: Revista de crítica literaria latinoamericana / Journal of Latin American Literary Criticism Cartografías de la mirada, del mapa virtual al recorrido afectivo: la ciudad y sus afueras en $L a$ experiencia dramática, de Sergio Chejfec.

Nancy, Jean-Luc. La ciudad a lo lejos. Buenos Aires, Manantial: 2013.

Rancière, Jacques. El espectador emancipado. Manantial, Buenos Aires, 2010.

Sebald, W.G. Sobre la historia natural de la destrucción. Anagrama, Barcelona, 2003.

$(\infty))$ EY ULIS DSale?
New articles in this journal are licensed under a Creative Commons Attribution 4.0 United States License.

This site is published by the University Library System, University of Pittsburgh as part of its D-Scribe Digital Publishing Program and is cosponsored by the University of Pittsburgh Press. 